Supporting Information for

\title{
A New Concept of Radiation Detection Based on a Fluorochromic
}

\section{and Piezochromic Nanocluster}

Huangjie Lu, ${ }^{\ddagger} \|$ Huiliang Hou, ${ }^{\ddagger} \|$ Yu-Chang Hou, ${ }^{\S}$ Zhaofa Zheng, ${ }^{\ddagger} \|$ Yingying Ma, ${ }^{\perp}$ Zhengyang Zhou, ${ }^{\#}$ Xiaofeng Guo, ${ }^{\nabla}$ Qing-Jiang Pan, ${ }^{*,}$ Yonggang Wang, ${ }^{*, \perp}$ Yuan Qian, ${ }^{\ddagger}, \|$ Jian-Qiang Wang, ${ }^{\ddagger}, \|$ and Jian Lin $^{*, \dagger}$

${ }^{\dagger}$ School of Nuclear Science and Technology, Xi'an Jiaotong University, Xi'an, 710049, P. R. China

${ }^{\S}$ Key Laboratory of Functional Inorganic Material Chemistry (Ministry of Education), School of Chemistry and Materials Science, Heilongjiang University, Harbin, 150080, P. R. China

${ }^{\ddagger}$ Key Laboratory of Interfacial Physics and Technology, Shanghai Institute of Applied Physics, Chinese Academy of Sciences, 2019 Jia Luo Road, Shanghai 2018oo, China

${ }^{\perp}$ Center for High Pressure Science and Technology Advanced Research (HPSTAR) Beijing, 10oo94, P. R. China

\#Shanghai Institute of Ceramics, Chinese Academy of Sciences, Shanghai 200050, P. R. China

Department of Chemistry and Alexandra Navrotsky Institute for Experimental Thermodynamics, Washington State University Pullman, WA 99164-4630, USA

"University of Chinese Academy of Sciences No.19(A) Yuquan Road, Shijingshan District, Beijing, 10oo49, P. R. China 


\section{Experimental Procedures}

\section{Materials and Synthesis}

Caution! Caution! Th-232 used in this study is an emitter with the daughter of radioactive Ra-228. All of the thorium compounds used and investigated were operated in an authorized laboratory designed for actinide element studies. Standard protections for radioactive materials should be followed.

Materials. $\mathrm{Th}\left(\mathrm{NO}_{3}\right)_{4} \cdot 6 \mathrm{H}_{2} \mathrm{O}$ (99.9\%, Changchun Institute of Applied Chemistry, Chinese Academy of Sciences), 2,2':6',2"--terpyridine-4'-carboxylic acid (HTPC) (99\%, Jilin Chinese Academy of Sciences Yanshen Technology Co., Ltd), DMF (99.5\%, Aladdin), $\mathrm{CH}_{3} \mathrm{COOH}$ (AR, $\geq 99.5 \%$, Sinopharm Chemistry Reagent Co., Ltd), and $\mathrm{CH}_{3} \mathrm{CH}_{2} \mathrm{COOH}$ (AR, $\geq 99.5 \%$, Sinopharm Chemistry Reagent Co., Ltd) were used as received from commercial suppliers without further purification.

Synthesis. A mixture of Th $\left(\mathrm{NO}_{3}\right)_{4} \cdot 6 \mathrm{H}_{2} \mathrm{O}(29.4 \mathrm{mg}, 0.05 \mathrm{mmol}), \mathrm{CH}_{3} \mathrm{COOH}(2 \mathrm{O} \mu \mathrm{L}), \mathrm{CH}_{3} \mathrm{CH}_{2} \mathrm{COOH}(100 \mu \mathrm{L})$, HTPC (13.8 mg, $0.05 \mathrm{mmol})$, DMF ( $1 \mathrm{~mL})$, and deionized water $(1 \mathrm{~mL})$ were loaded into a $5 \mathrm{~mL}$ vials. The vial was sealed and heated to $100{ }^{\circ} \mathrm{C}$ for $48 \mathrm{~h}$ and then cooled to room temperature under ambient condition. Colorless block crystals of Th-1o1 were isolated after being washed with ethanol and allowed to air-dry at room temperature. The yield of Th-1o1 was calculated to be $26.5(5) \%$ based on HTPC.

\section{Characterizations}

Crystallographic Analysis. Single crystal X-ray diffraction measurements were performed using a Bruker D8-Venture single crystal X-ray diffractometer equipped with an $\mathrm{I} \mu \mathrm{S} 3.0$ microfocus X-ray source (Mo-K $\alpha$ radiation, $\lambda=0.71073 \AA$ ) and a CMOS detector at $298 \mathrm{~K}$. The data frames were collected using the program $\mathrm{APEX}_{3}$ and processed using the program SAINT routine in $\mathrm{APEX}_{3}$. The structures were solved by the direct method and refined on $\mathrm{F}^{2}$ by full-matrix least-squares methods using SHELXTL-2014 program. ${ }^{1}$ Powder Xray diffraction (PXRD) data were collected from 5 to $50^{\circ}$ with a step of $0.02^{\circ}$ and the time for data collection was $0.5 \mathrm{~s}$ on a Bruker D8 Advance diffractometer with $\mathrm{Cu} K \alpha$ radiation $(\lambda=1.54056 \AA)$ and a Lynxeye onedimensional detector. During the structural refinements of Th-1o1, a large residual electron density was located in difference Fourier maps with a short distance $(\sim 0.7 \AA)$ to $\mathrm{O}_{7}$, indicating the disorder of $\mathrm{O}_{7}$. The disorder was treated as two sites, $\mathrm{O}_{7} \mathrm{~A} / \mathrm{O}_{7} \mathrm{~B}$ with refined occupancies of about $52 \% / 48 \%$. The bond distances of Th-O7A range from 2.305(6) to 2.315(6) $\AA$ and those of Th- $\mathrm{O}_{7} \mathrm{~B}$ range from 2.481(6) to 2.56o(6) $\AA$. Bond-valence sum calculations were conducted, suggesting that the BVS for $\mathrm{O}_{7} \mathrm{~A}$ and $\mathrm{O}_{7} \mathrm{~B}$ are 2.035 and 1.188, respectively. Therefore, $\mathrm{O}_{7} \mathrm{~A}$ and $\mathrm{O}_{7} \mathrm{~B}$ can be assigned to $\mathrm{O}^{2-}$ is $\mathrm{OH}^{-}$, respectively.

UV-Vis and Photoluminescence Spectroscopy. . The solid-state UV-Vis absorption and photoluminescence spectra upon UV radiation were recorded on a Craic Technologies microspectrophotometer from a single crystal of Th-101. Crystals were placed on quartz slide, and data was 
collected after auto-set optimization. When the $365 \mathrm{~nm}$ excitation light was selected, an optical filter masking signal below $420 \mathrm{~nm}$ was applied to eliminate the interference of excitation light. The photoluminescence spectra upon X-ray radiation ( $\mathrm{Cu} \mathrm{K \alpha}$ radiation source, $60 \mathrm{kV}, 7.2, \mathrm{kGy} / \mathrm{h})$ were collected on an Edinburgh Instruments $\mathrm{FS}_{5}$ steady state spectrofluorometer from a Th-101 tablet with $365 \mathrm{~nm} \mathrm{UV}$ excitation. The decay curves were collected on an Edinburgh Instruments FLS 98o spectrometer from bulk samples. PL quantum-yield (PLQY) was recorded using a HORIBA scientific Fluorolog-3 spectrophotometer with a quantum-yield accessory.

Characterizations under high pressure (HP). A symmetric diamond-anvil-cell (DAC) with type-II diamonds polished to diameters of $400 \mu \mathrm{m}$ was used to generate HP up to $30 \mathrm{GPa}$. Steel gaskets were preindented to about $40 \mu \mathrm{m}$ thick, and then $200 \mu \mathrm{m}$ holes were drilled to serve as the sample chambers. A single crystal of the sample was placed inside the sample chamber together with several ruby balls. Pressure was calibrated by the Ruby fluorescence method. Silicone oil was employed as the pressure transition medium. In-situ HP Vis-NIR absorption spectra were recorded using a home-designed spectroscopy system (Gora-UVN-FL, Ideaoptics) with a Xeon light source. The bandgap is determined by extrapolating the linear portion of $\alpha^{1 / 2} \sim h v$ (direct bandgap) or $\alpha^{2} \sim h v$ (indirect bandgap), where $\alpha$ is absorption coefficient, $h$ is Planck constant, and $v$ is photon frequency.

Fourier Transform Infrared Spectroscopy. The IR spectra were recorded using a FTIR spectrometer (Thermo Nicolet 6700 spectrometer) equipped with a diamond attenuated total reflectance (ATR) accessory in the range of $400-4000 \mathrm{~cm}^{-1}$.

Thermalgravimetric Analysis (TGA). TGA was carried out on a NETZSCH STA 449 F3 jupiter instrument in the range of $30-900{ }^{\circ} \mathrm{C}$ under a nitrogen flow at a heating rate of $10^{\circ} \mathrm{C} / \mathrm{min}$.

Electron Paramagnetic Resonance (EPR) Study. The EPR measurements were performed on a JEOLFA20o spectrometer at X-band with $100-\mathrm{kHz}$ field modulation. The EPR spectra of nonirradiated and irradiated samples were recorded at room temperature and the microwave power used was $1.0 \mathrm{~mW}$.

Scanning Electron Microscopy and Energy-Dispersive Spectroscopy (SEM-EDS) Analysis. SEM-EDS study on Th-101 was performed on a Zeiss Merlin Compact LEO 1530 VP scanning electron microscope with the energy of the electron beam and spectra acquisition time being $15 \mathrm{kV}$ and 6os, respectively (Fig. S15).

Radiolytic Stability. The radiation resistance of Th-101 was examined by irradiating the powdery sample with X-ray, $\beta$-ray, or $\gamma$-ray under ambient conditions. The as-synthesized samples were washed with deionized water and ethanol, dried under ambient condition, and sealed in polyethylene bags. X-ray, $\beta$-ray and $\gamma$-ray radiations were provided by a $\mathrm{Cu} \mathrm{K} \alpha$ radiation source $\left(6 \mathrm{o} \mathrm{kV},{ }_{12} \mathrm{~W}\right)$, a custom-built electron cyclotron $(1.2 \mathrm{MeV})$, and a ${ }^{60} \mathrm{Co}$ irradiation source $\left(2.22 \times 10^{15} \mathrm{~Bq}\right)$, respectively. Th-101 was irradiated with accumulated doses with dose rates of 7.2, 150, and $11.8 \mathrm{kGy} / \mathrm{h}$ for X-ray, $\beta$-ray, $\gamma$-ray, respectively, and the 
dose rates of radiations were determined by commercialized alanine dosimeters. PXRD and FTIR analyses on the irradiated samples were performed to confirm the radiation resistance of Th-101.

\section{Computational Details}

On the basis of experimental X-ray crystal diffraction, the structure of Th-101 was fully optimized as shown in Figure S14. Since Th-101 contains eight bulky TPC ligands, simplified models Th-101-m and Th-1o1-d with one and two TPC ligands, respectively, were optimized to save computational cost. The rest TPCs were substituted by $\mathrm{CH}_{3} \mathrm{COO}^{-}$anions in the simplified models. To examine the effect of $\pi-\pi$ stacking of TPCs on the spectroscopic property of molecular complex, the neighboring TPC dimer (interlamellar distance of $3.685 \AA$ A), namely (TPC) ${ }_{2}-\mathbf{1 0 1}$, was isolated from the CIF file and subjected to the theoretical calculation. For comparison, calculation on the TPC dimer (interplanar distance of $3.178 \AA$ ) of Th-SINAP-10o, namely $(\mathrm{TPC})_{2}$-10o, was performed. ${ }^{2}$

Unless otherwise noted, Priroda code was exploited to optimize structure in the gas phase without any symmetry constraints." 4 A scalar relativistic four-component all-electron approach was employed, associated with the PBE functional of the generalized gradient approximation (GGA) ${ }^{5}$ and all-electron correlation-consistent double-ৎ polarized quality basis sets ${ }^{3}$. Frequency calculations were conducted. No imaginary frequencies were obtained and confirmed the nature of the minimal point on the potential energy surface. Population-based Mayer ${ }^{6}$ bond orders were calculated.

Electronic structures and $\pi-\pi$ stacking interaction energies were calculated with ADF 2014 code. ${ }^{7-9}$ An integration parameter of 6.0 was applied. We used the level of theory, including the ZORA scalar relativistic approach of van Lenthe et $\mathrm{al}^{10-13}$, PBE functional and Slater-type TZP basis sets. Regarding the (TPC) ${ }_{2}-\mathbf{1 0 o}$ and (TPC) $)_{2}-101$ dimers, the $\pi-\pi$ stacking between TPCs was explored by the energy decomposition analysis (EDA). The computed total interaction energy $\left(\mathrm{E}_{\mathrm{T}}\right)$ is expressed as $\mathrm{E}_{\mathrm{T}}=\mathrm{E}_{\text {Steric }}+\mathrm{E}_{\text {Orbit }}+\mathrm{E}_{\text {Disp }}$ and $\mathrm{E}_{\text {Steric }}=\mathrm{E}_{\text {Elec }}$ $+\mathrm{E}_{\text {Pauli }}$, where the sub-terms denote steric interaction, orbital attraction, dispersion interaction, electrostatic interaction, and Pauli repulsion, respectively. The Grimme's $D_{3}$ correction was used to describe the dispersion term. ${ }^{14}$, 15 Forty spin-allowed excited states of dimers (TPC) ${ }_{2}-\mathbf{1 0 0}$ and (TPC) ${ }_{2}$-101 were also calculated by the time-dependent density functional theory (TD-DFT). Electronic absorption transitions were attained. Considering the environmental effect, the Conductor-Like Screening Model $(\mathrm{COSMO})^{16,17}$ was used. The dielectric constant of water is 78.38. Klamt radii were taken as $\mathrm{H}=1.30 \AA$, $\mathrm{C}=$ $2.00 \AA$, $\mathrm{O}=1.72 \AA$ and $\mathrm{N}=1.83 \AA \AA^{.8-22}$ 


\section{Supplementary Figures}
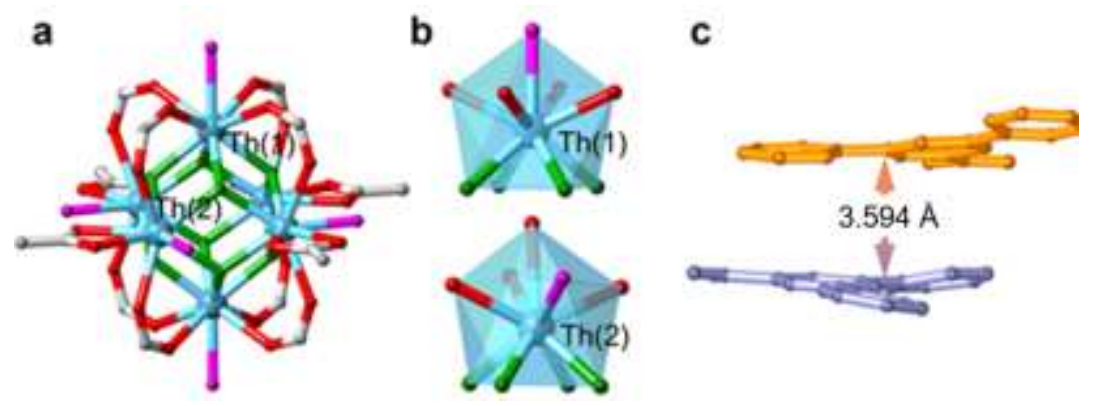

Figure S1. (a) Coordination environment of the hexameric $\left[\mathrm{Th}_{6}(\mathrm{OH})_{4} \mathrm{O}_{4}\left(\mathrm{H}_{2} \mathrm{O}\right)_{6}\right]^{12+}$ core. (b) Coordination environments of $\mathrm{Th}(1)$ and $\mathrm{Th}(2)$ cations. The Th atoms are shown in cyan; $\mathrm{C}$ atoms in gray, $\mathrm{O}$ atoms from $\mu_{3}-\mathrm{OH} /-\mathrm{O}$ in green, $\mathrm{H}_{2} \mathrm{O}$ in purple, and $\mathrm{O}$ atoms from bridging carboxylate groups are shown in red. (c) Side view showing the $\pi-\pi$ interaction of TPC moieties in Th-101. 


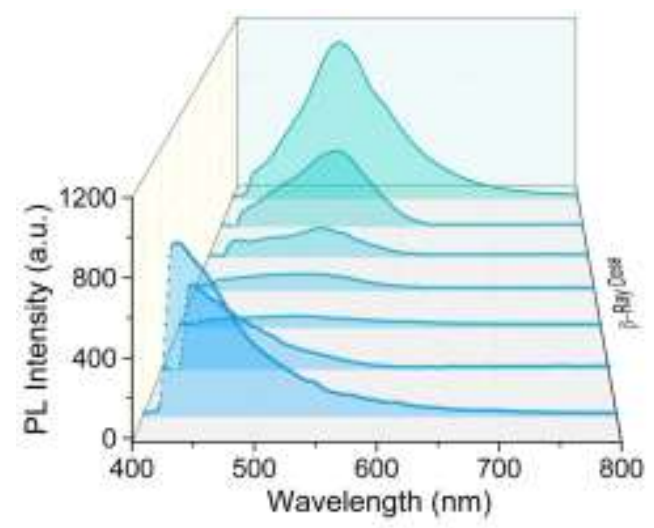

Figure S2. The PL spectra of Th-101 upon $\beta$-ray irradiation with increasing doses.
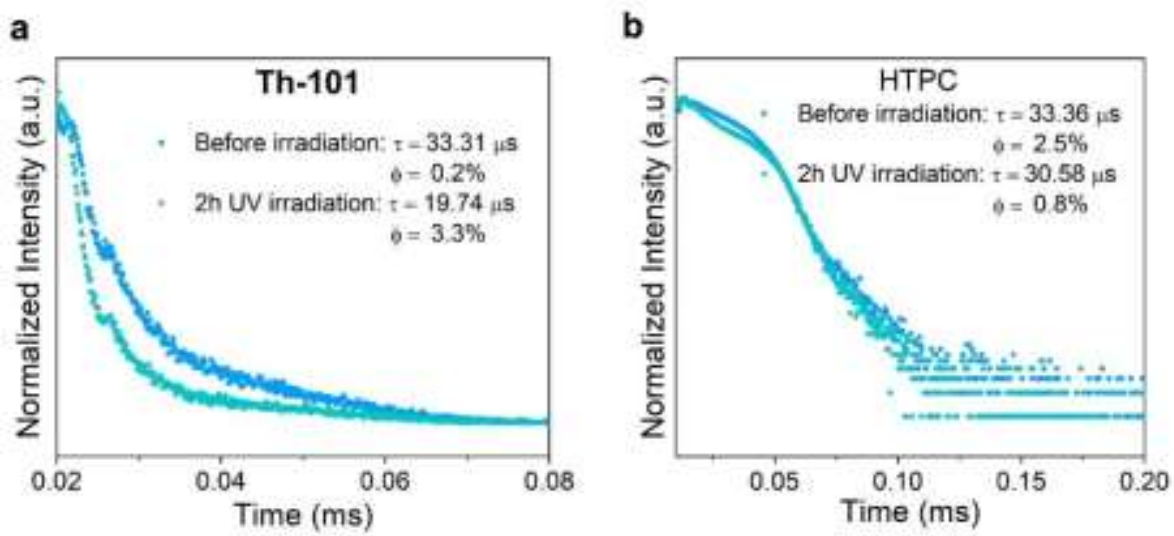

Figure $S_{3}$. Photoluminescence decay spectra and quantum yields of nonirradiated and UV irradiated (a) Th-101 and (b) HTPC. 
a

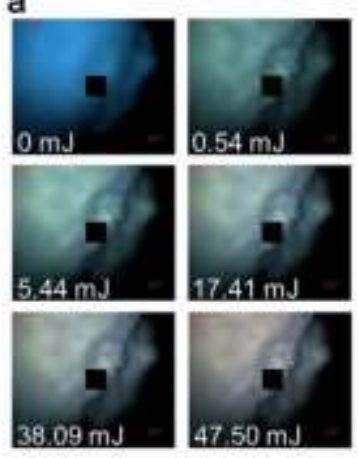

b

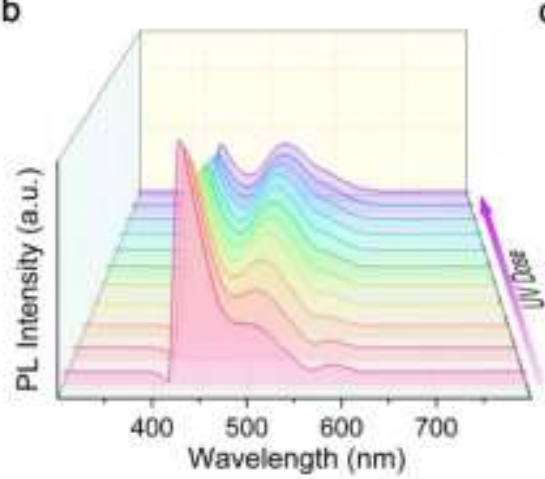

c

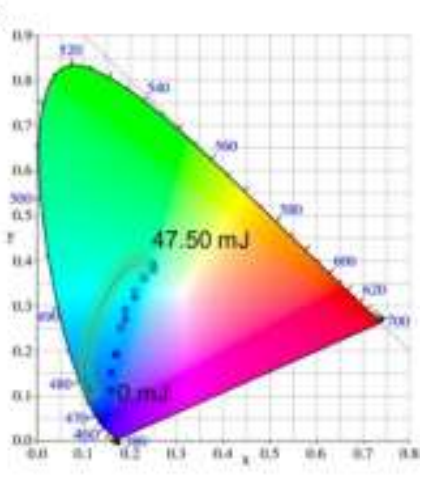

Figure S4. (a) Snapshots of HTPC ligand upon $365 \mathrm{~nm}$ UV irradiation. (b) Evolution of the PL spectra of TPC ligand upon $365 \mathrm{~nm}$ UV irradiation. (c) CIE chromaticity coordinates of TPC ligand as a function of irradiation time.

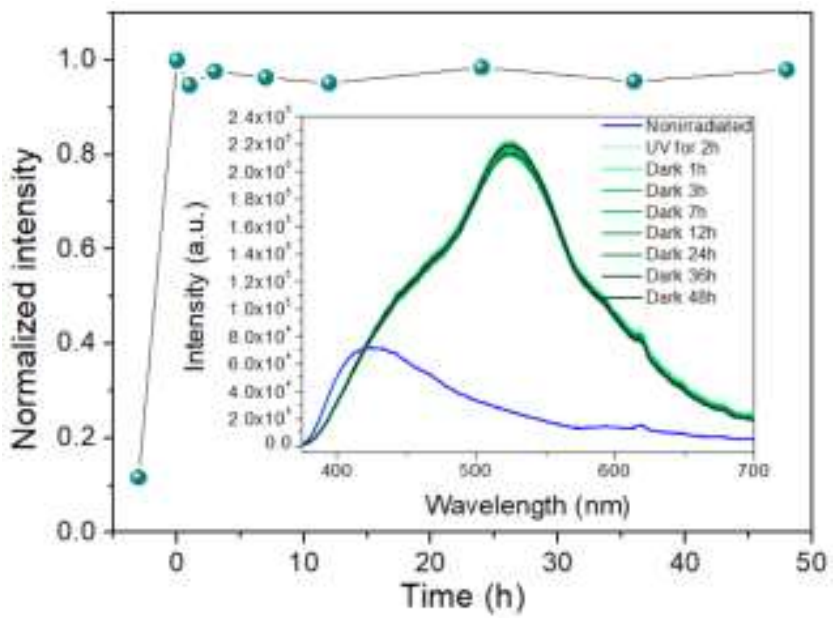

Figure S5. Time-dependent PL spectra (inset) and normalized PL intensity of irradiated Th-101 which is stored in dark under ambient condition. 

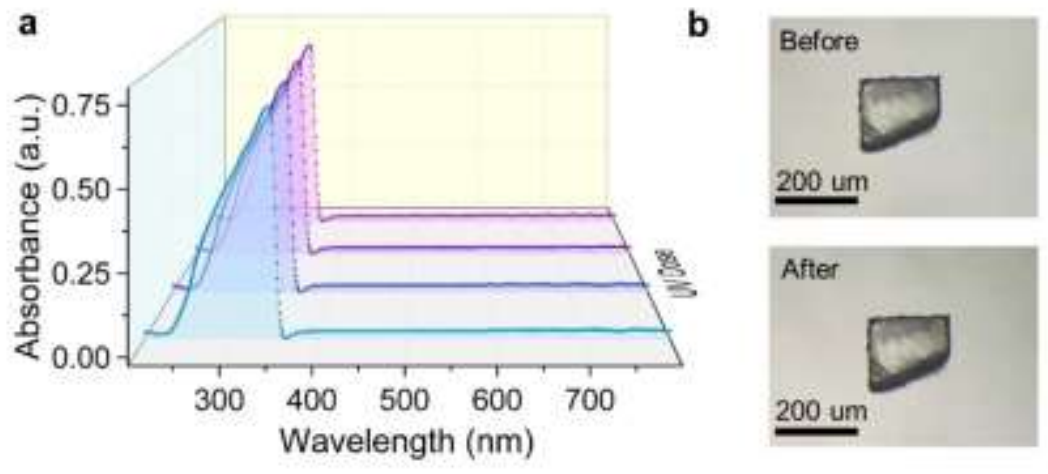

Figure S6. Evolution of and UV-Vis absorption spectra of Th-101 upon continuous UV irradiation (o to $59.22 \mathrm{~mJ})$. (b) The color of Th-101 crystal before and after UV irradiation (59.22 mJ).

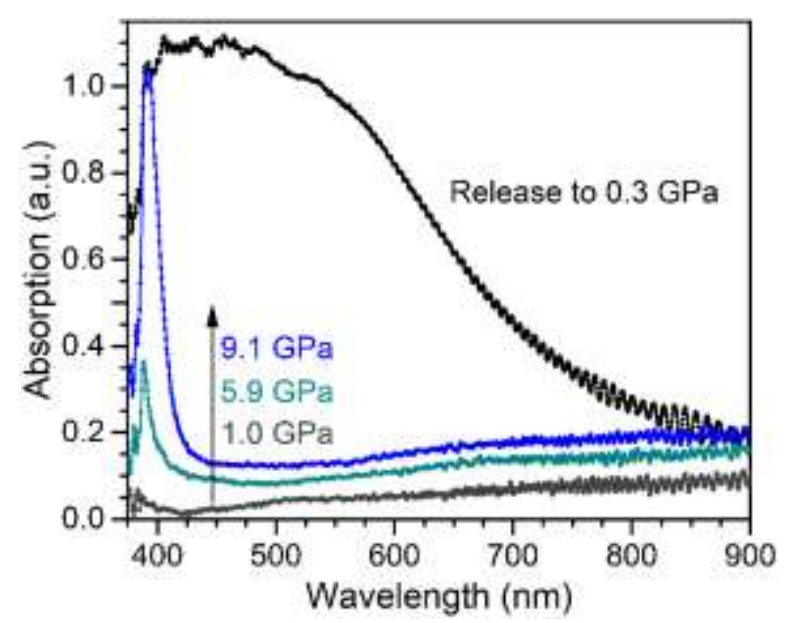

Figure S7. UV-Vis absorption spectra of Th-101 upon compression and after pressure releasing. 


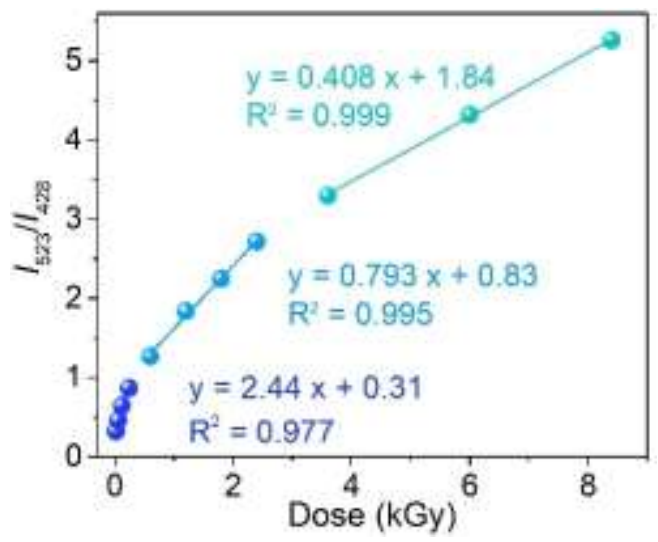

Figure S8. Linear fittings of the intensity ratio $I_{523} / I_{428}$ as a function of X-ray dosage.

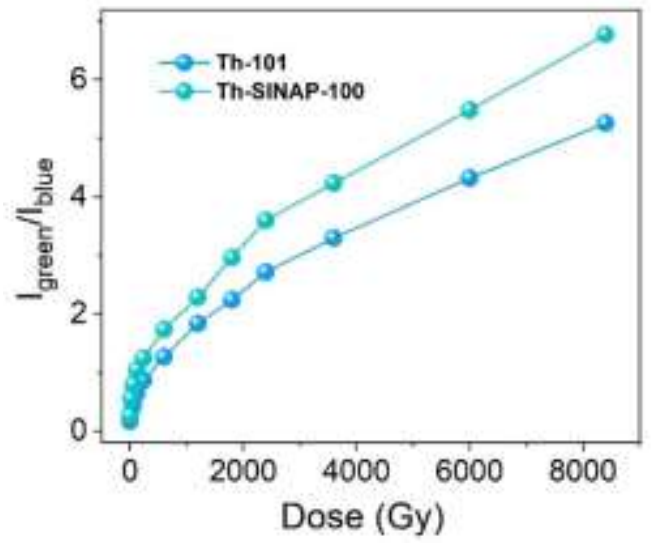

Figure S9. Comparison of the PL responses between Th-SINAP-100 and Th-101. 


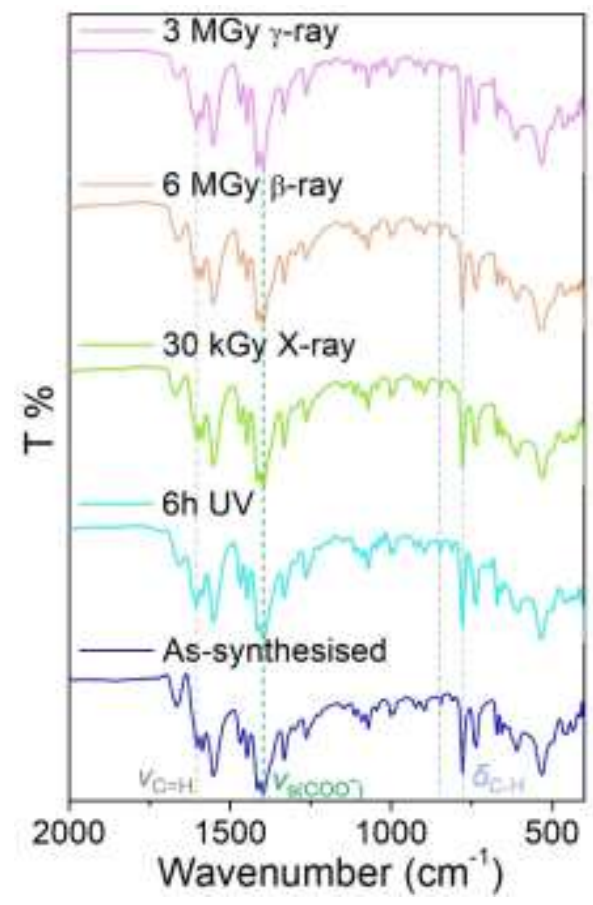

Figure S1o. FTIR spectra of Th-101 before and after irradiation with UV, $\beta$-ray, $\gamma$-ray, and X-ray.

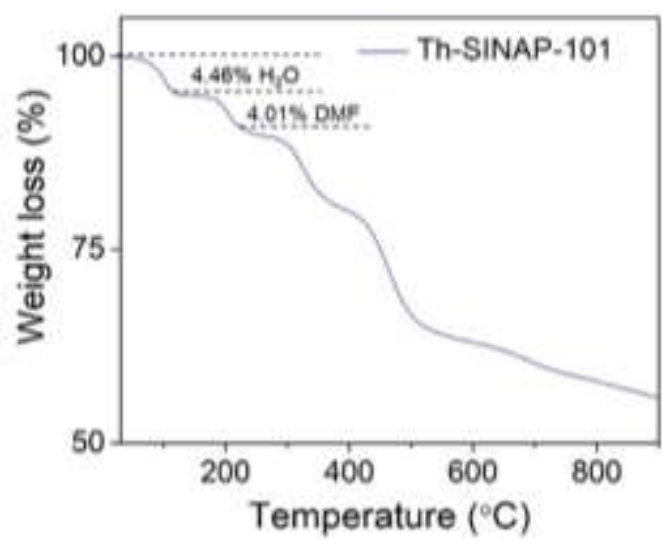

Figure S11. TGA curve showing that Th-101 is thermally stable up to $215^{\circ} \mathrm{C}$. The weight loss from $30-215^{\circ} \mathrm{C}$ corresponds to the departure of guest species. 


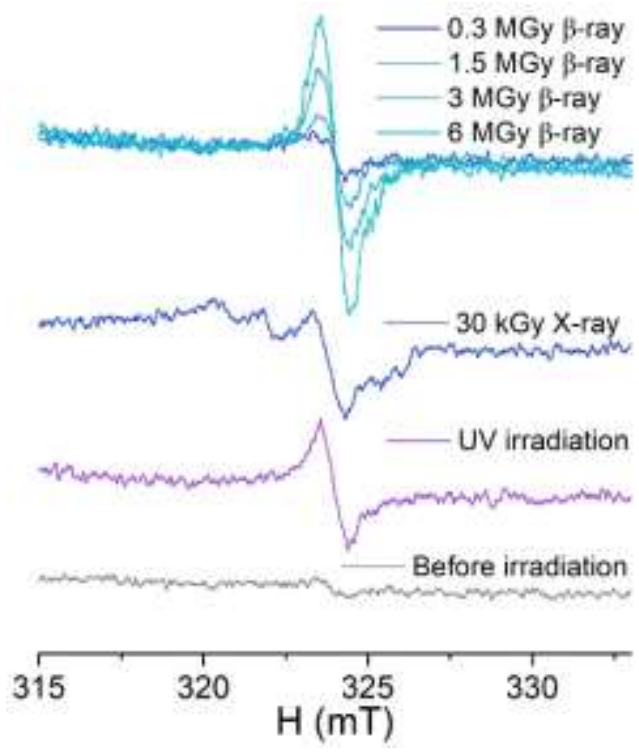

Figure S12. EPR spectra of nonirradiated, UV, X-ray, and $\beta$-ray irradiated Th-101.

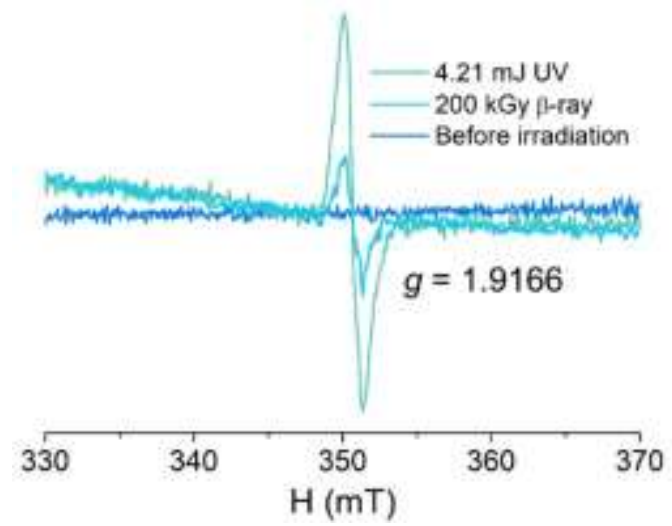

Figure S13. EPR spectra of TPC ligand before and after UV and $\beta$-ray irradiation. 


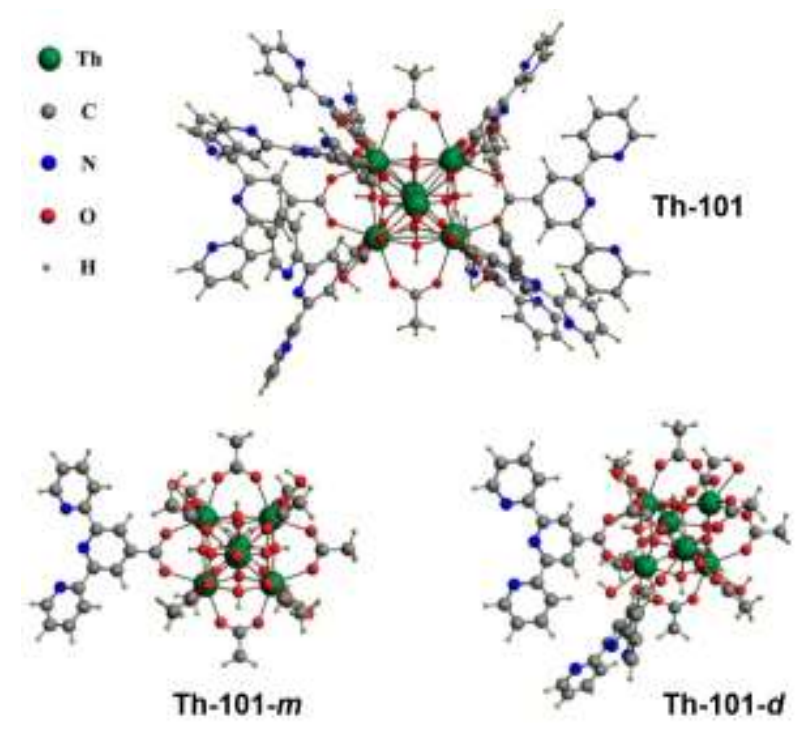

Figure S14. Optimized structures of Th-101 and ligand-simplified models Th-101-m and Th-101-d.
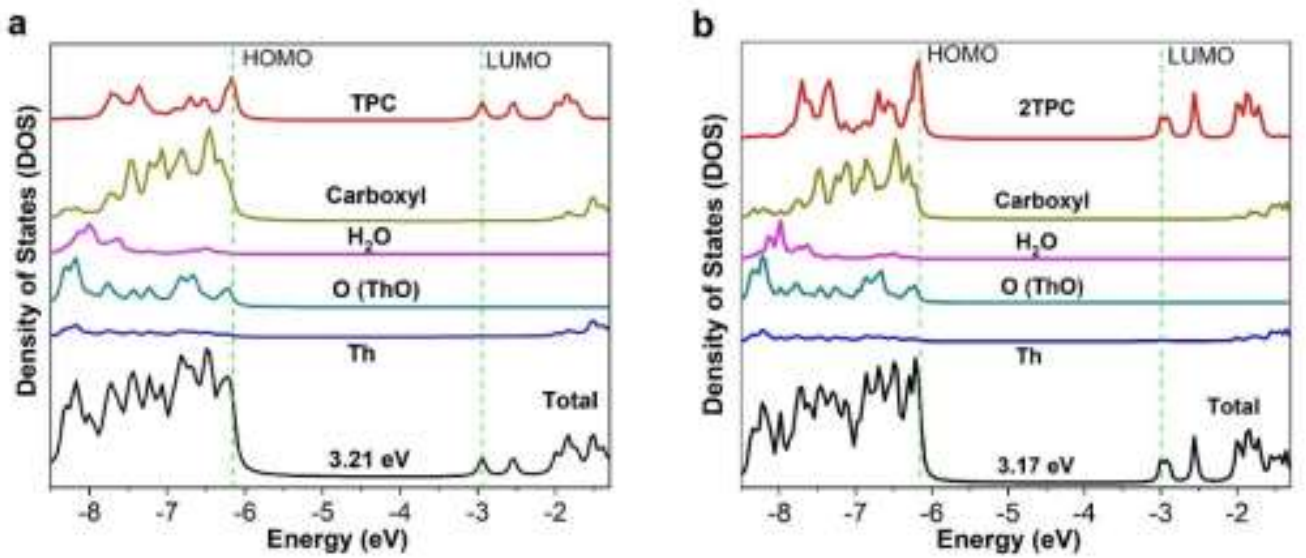

Figure S15. Density of states (DOSs) of (a) Th-101-m and (b) Th-101-d. 
a

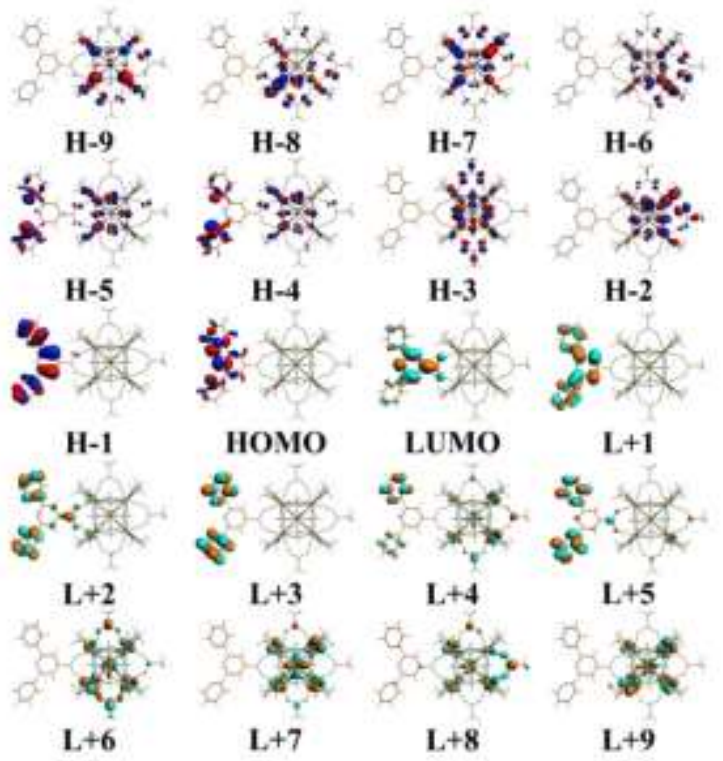

b
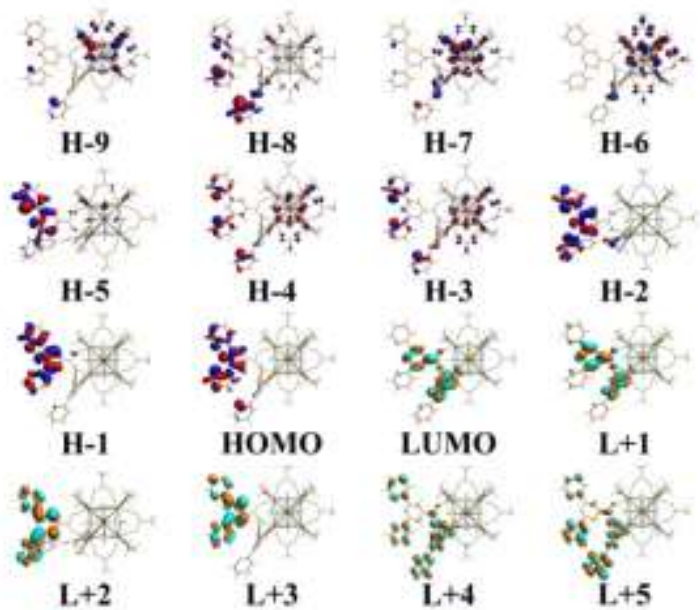

$\mathbf{L}+\mathbf{1}$
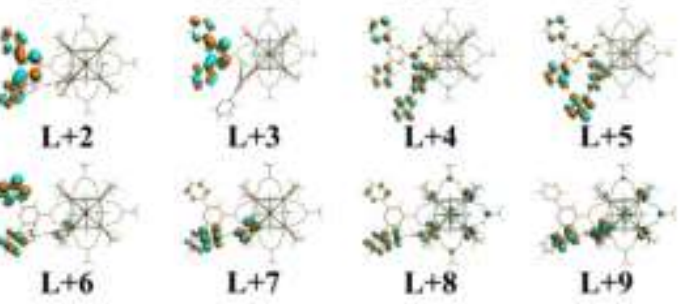

Figure S16. Diagrams of some orbitals of (a) Th-101-m and (b) Th-101-d. 


\section{Supplementary Tables}

Table S1. Crystallographic data of Th-101.

\begin{tabular}{|c|c|}
\hline Sample & Th-101 \\
\hline Mass & 4078.71 \\
\hline Color & Colorless \\
\hline Habit & Block \\
\hline Space group & $I_{4} / \mathrm{m}$ \\
\hline$a(\AA)$ & $14.7962(3)$ \\
\hline$b(\AA)$ & $14.7962(3)$ \\
\hline$c(\AA)$ & $40.1724(18)$ \\
\hline$\alpha(\mathrm{deg})$ & 90 \\
\hline$\beta(\mathrm{deg})$ & 90 \\
\hline$\gamma(\operatorname{deg})$ & 90 \\
\hline$V\left(\AA^{3}\right)$ & $8794.8(5)$ \\
\hline$Z$ & 2 \\
\hline$T(\mathrm{~K})$ & $293(2)$ \\
\hline$\lambda(\AA)$ & 0.71073 \\
\hline $\operatorname{Max} 2 \theta(\mathrm{deg})$ & 54.960 \\
\hline$\rho_{\text {calcd }}\left(\mathrm{g} \mathrm{cm}^{-3}\right)$ & 1.540 \\
\hline$\mu(\mathrm{Mo} \mathrm{Ka})$ & 0.71073 \\
\hline$R_{1}$ & 0.0269 \\
\hline$w R_{2}$ & 0.0630 \\
\hline$R_{\text {int }}$ & 0.0423 \\
\hline GOF & 1.178 \\
\hline
\end{tabular}


Table S2. The CIE chromaticity coordinates (x, y) of PL upon irradiation with different UV and X-ray dose for Th-1o1.

\begin{tabular}{cccc}
\hline Dosage $(\mathrm{mJ})$ & CIE coordinates $(\mathrm{x}, \mathrm{y})$ & Dosage $(\mathrm{Gy})$ & CIE coordinates $(\mathrm{x}, \mathrm{y})$ \\
\hline 0 & $(0.18,0.15)$ & 0 & $(0.183,0.126)$ \\
0.25 & $(0.21,0.24)$ & 20 & $(0.191,0.166)$ \\
0.49 & $(0.23,0.29)$ & 60 & $(0.200,0.202)$ \\
3.95 & $(0.28,0.42)$ & 120 & $(0.208,0.239)$ \\
14.80 & $(0.29,0.44)$ & 240 & $(0.216,0.268)$ \\
59.22 & $(0.30,0.45)$ & 600 & $(0.226,0.308)$ \\
& & 1200 & $(0.236,0.341)$ \\
& & 1800 & $(0.241,0.358)$ \\
& & 2400 & $(0.247,0.375)$ \\
& & 3600 & $(0.253,0.390)$ \\
& & 6000 & $(0.262,0.410)$ \\
& & 8400 & $(0.269,0.426)$ \\
\hline
\end{tabular}


Table S3. The comparison of $\gamma$ and $\beta$ radiation resistance of different materials.

\begin{tabular}{|c|c|c|c|c|}
\hline MOFs & Structural Type & $\beta$ irradiation & $\gamma$ irradiation & Reference \\
\hline Th-101 & Cluster & 6 MGy & 3 MGy & This work \\
\hline Th-SINAP-10o & Cluster & 1 MGy & 1 MGy & 1 \\
\hline$\left[\left(\mathrm{CH}_{3}\right)_{2} \mathrm{NH}_{2}\right]\left[\mathrm{UO}_{2}(\mathrm{Lr})\right]$ & MOF & $200 \mathrm{kGy}$ & $\mathrm{N} / \mathrm{A}$ & 2 \\
\hline SCU-100 & MOF & $100 \mathrm{kGy}$ & N/A & 3 \\
\hline SCU-101 & MOF & $200 \mathrm{kGy}$ & N/A & 4 \\
\hline FJSM-InMOF & MOF & $200 \mathrm{kGy}$ & $\mathrm{N} / \mathrm{A}$ & 5 \\
\hline$\left.\left[\mathrm{Ni}_{3} \mathrm{Th}_{6}\left(\mu_{3}-\mathrm{O}\right)_{4}\left(\mu_{3} \mathrm{OH}\right)_{4}(\mathrm{IN})_{12}\right)\left(\mathrm{H}_{2} \mathrm{O}\right)_{12}\right] \cdot(\mathrm{OH})_{6}$ & MOF & $400 \mathrm{kGy}$ & $100 \mathrm{kGy}$ & 6 \\
\hline SCU-200 & MOF & $\mathrm{N} / \mathrm{A}$ & $200 \mathrm{kGy}$ & 7 \\
\hline SIFSIX-3-Cu & MOF & $50 \mathrm{kGy}$ & $50 \mathrm{kGy}$ & 8 \\
\hline MIL-10o(Al) & MOF & N/A & $2000 \mathrm{kGy}$ & 9 \\
\hline
\end{tabular}


Table S4. Selected bond distances ( $⿱$ ) of Th-1o1 from SCXRD analysis.

\begin{tabular}{|c|c|c|}
\hline Assignment & Bond & Distance $(\AA)$ \\
\hline \multirow{2}{*}{$\mathrm{Th}-\mathrm{O}_{\mathrm{W}}$} & $\mathrm{Th}_{1}-\mathrm{O}_{3}$ & $2.684(6)$ \\
\hline & $\mathrm{Th}_{2}-\mathrm{O}_{2}$ & $2.632(4)$ \\
\hline \multirow{3}{*}{ Th- $-\mathrm{O}_{\text {oxo }}$} & Th1-O7A & $2.315(6)$ \\
\hline & Th2-O7A & $2.312(6)$ \\
\hline & Th2-O $\mathrm{O}_{7} \mathrm{~A}^{\prime}$ & $2.305(6)$ \\
\hline \multirow{3}{*}{ Th- $\mathrm{O}_{\text {hydroxo }}$} & Th1-O $\mathrm{O}_{7} \mathrm{~B}$ & $2.560(6)$ \\
\hline & Th2-O7 B & $2.481(6)$ \\
\hline & Th2-O ${ }_{7} \mathrm{~B}^{\prime}$ & $2.493(6)$ \\
\hline \multirow{2}{*}{$\mathrm{Th}-\mathrm{O}_{\mathrm{TPC}}$} & Th1-O1 & $2.483(3)$ \\
\hline & Th2- $\mathrm{O}_{5}$ & $2.482(3)$ \\
\hline \multirow{2}{*}{$\mathrm{Th}-\mathrm{O}_{\mathrm{CH}_{3} \mathrm{COO}}$} & $\mathrm{Th}_{2}-\mathrm{O}_{4}$ & $2.689(4)$ \\
\hline & Th2-O6 & $2.545(4)$ \\
\hline$\pi-\pi$ stacking distance & TPC-TPC $\left(\mathrm{N}_{1}, 3\right)$ & 3.594 \\
\hline
\end{tabular}


Table S5. Optimized bond lengths ( $(̊)$ for the experimentally-synthesized complex and selected model ones.

\begin{tabular}{|c|c|c|c|c|c|}
\hline & & Th-O ${ }_{\text {oxo/hydroxo }}{ }^{a}$ & Th-O $\mathrm{O}_{\text {TPC }}$ & Th-O $\mathrm{O}_{\mathrm{COO}}$ & Th- $\mathrm{O}_{\mathrm{w}}$ \\
\hline Th-101 & Calc. & $\begin{array}{c}2.410 \\
(2.290-2.545)^{b}\end{array}$ & $\begin{array}{c}2.506 \\
\left(2.43^{-2.609)}\right.\end{array}$ & $\begin{array}{c}2.534 \\
\left(2.447^{-2} .577\right)\end{array}$ & $\begin{array}{c}2.747 \\
(2.729-2.759)\end{array}$ \\
\hline Th-101-m & Calc. & $\begin{array}{c}2.411 \\
(2.287-2.531)\end{array}$ & $\begin{array}{c}2.531 \\
(2.465-2.597)\end{array}$ & $\begin{array}{c}2.515 \\
(2.448-2.588)\end{array}$ & $\begin{array}{c}2.747 \\
\left(2.724^{-2.773}\right)\end{array}$ \\
\hline Th-1 & Calc. & $\begin{array}{c}2.410 \\
(2.290-2.526)\end{array}$ & $\begin{array}{c}2.494 \\
\left(2.453^{-2.578)}\right.\end{array}$ & $\begin{array}{c}2.520 \\
(2.448-2.583)\end{array}$ & $\begin{array}{c}2.747 \\
(2.723-2.758)\end{array}$ \\
\hline
\end{tabular}

a Four types of oxo atoms include $\mathrm{O}_{\text {oxo/hydroxo }}$ (thorium cluster), $\mathrm{O}_{\text {TPC }}$ (TPC ligand), $\mathrm{O}_{\mathrm{HCOO}}$ (HCOO or $\mathrm{CH}_{3} \mathrm{COO}$ ligand), and $\mathrm{O}_{\mathrm{W}}$ (water).

$\mathrm{b}$ The average value along with the range of all values in parentheses.

Table S6. Bond orders of the experimentally-synthesized complex and selected model ones.

\begin{tabular}{ccccc}
\hline & Th-O $\mathrm{O}_{\text {oxo/hydroxo }}$ & Th- $\mathrm{O}_{\text {TPC }}$ & Th-O $\mathrm{COO}$ & Th-O \\
\hline Th-101-m & 0.59 & 0.48 & 0.51 & 0.39 \\
Th-101-d & $0.41-0.77)^{\mathrm{a}}$ & $(0.43-0.53)$ & $(0.45-0.48)$ & $(0.38-0.39)$ \\
& 0.59 & 0.52 & 0.51 & 0.39 \\
Th-101 & $0.41-0.78)$ & $(0.45-0.55)$ & $(0.45-0.58)$ & $(0.38-0.40)$ \\
& 0.59 & 0.51 & 0.49 & 0.39 \\
$(0.40-0.78)$ & $(0.43-0.56)$ & $(0.45-0.57)$ & $(0.39-0.40)$ \\
\hline
\end{tabular}

${ }^{\mathrm{a}}$ The average value along with the range of all values in parentheses.

Table S7. Featured absorptions of dimeric (TPC) ${ }_{2}$ calculated at the TD-DFT level. 


\begin{tabular}{|c|c|c|c|c|c|}
\hline & $\lambda(\mathrm{nm})^{\mathrm{a}}$ & $E(e V)^{a}$ & $f^{\mathrm{b}}$ & Configuration & Weight $>0.1$ \\
\hline \multirow[t]{5}{*}{$(\mathrm{TPC})_{2}-\mathbf{1 0 0}$} & $425^{c}$ & 2.92 & 0.0055 & 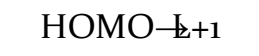 & 0.5513 \\
\hline & & & & $\mathrm{H}-\mathrm{-}-\mathrm{\uplus UMO}$ & 0.3784 \\
\hline & $394^{d}$ & 3.15 & 0.1319 & $\mathrm{H}-4-\mathrm{UMO}$ & 0.4330 \\
\hline & & & & H-3-せUMO & 0.3151 \\
\hline & & & & $\mathrm{H}-2-\mathrm{t}+1$ & $0.155^{8}$ \\
\hline \multirow[t]{5}{*}{$(\mathrm{TPC})_{2}-\mathbf{1 0 1}$} & $402^{c}$ & 3.09 & 0.0046 & HOMO-UMO & 0.5320 \\
\hline & & & & H-3-せUMO & 0.2191 \\
\hline & & & & $\mathrm{H}-2-\mathrm{EUMO}$ & 0.1611 \\
\hline & $375^{\mathrm{d}}$ & $3 \cdot 31$ & 0.1189 & $\mathrm{H}-3-\mathrm{UMO}$ & 0.4811 \\
\hline & & & & $\mathrm{H}-2-\mathrm{UUMO}$ & 0.3014 \\
\hline
\end{tabular}

${ }^{\text {a }}$ Calculated absorption transitions in $\mathrm{nm}$ and $\mathrm{eV}$.

${ }^{\mathrm{b}}$ Oscillator strength $(f)$.

${ }^{\mathrm{c}}$ The adsorption transition in the longest wavelength.

d The adsorption transition with the largest oscillator strength. 


\section{Supplementary References}

1. Sheldrick, G. M. SHELXT - Integrated space-group and crystal-structure determination. Acta Crystallogr. Sect. A 2015, 71, 3-8.

2. Lu, H.; Xie, J.; Wang, X.-Y.; Wang, Y.; Li, Z.-J.; Diefenbach, K.; Pan, Q.-J.; Qian, Y.; Wang, J.-Q.; Wang, S.; Lin, J. Visible colorimetric dosimetry of UV and ionizing radiations by a dual-module photochromic nanocluster. Nat. Commun. 2021, 12, 2798.

3. Laikov, D. N. A new class of atomic basis functions for accurate electronic structure calculations of molecules. Chem. Phys. Lett. 2005, 416, 116-120.

4. Laikov, D. N.; Ustynyuk, Y. A. PRIRODA-04: a quantum-chemical program suite. New possibilities in the study of molecular systems with the application of parallel computing. Russ. Chem. Bull. 2005, 54, 820-826.

5. Perdew, J. P.; Burke, K.; Ernzerhof, M. Generalized gradient approximation made simple. Phys. Rev. Lett. 1996, 77, 3865-3868.

6. Mayer, I. Simple Theorems, Proofs, and Derivations in Quantum Chemistry. Springer US: 2003.

7. te Velde, G.; Bickelhaupt, F. M.; Baerends, E. J.; Fonseca Guerra, C.; van Gisbergen, S. J. A.; Snijders, J. G.; Ziegler, T. Chemistry with ADF. J. Comput. Chem. 2oo1, 22, 931-967.

8. Fonseca Guerra, C.; Snijders, J. G.; te Velde, G.; Baerends, E. J. Towards an order-N DFT method. Theor. Chem. Acc. 1998, 99, 391-403.

9. Baerends, E. J.; Ziegler, T.; Autschbach, J.; Bashford, D.; Bérces, A.; Bickelhaupt, F. M.; Bo, C.; Boerrigter, P. M.; Cavallo, L.; Chong, D. P.; Deng, L.; Dickson, R. M.; Ellis, D. E.; van Faassen, M.; Fan, L.; Fischer, T. H.; Fonseca Guerra, C.; Franchini, M.; Ghysels, A.; Giammona, A.; van Gisbergen, S. J. A.; Götz, A. W.; Groeneveld, J. A.; Gritsenko, O. V.; Grüning, M.; Gusarov, S.; Harris, F. E.; van den Hoek, P.; Jacob, C. R.; Jacobsen, H.; Jensen, L.; Kaminski, J. W.; van Kesse, G.; Kootstra, F.; Kovalenko, A.; Krykunov, M. V.; van Lenthe, E.; McCormack, D. A.; Michalak, A.; Mitoraj, M.; Morton, S. M.; Neugebauer, J.; Nicu, V. P.; Noodleman, L.; Osinga, V. P.; Patchkovskii, S.; Pavanello, M.; Philipsen, P. H. T.; Post, D.; Pye, C. C.; Ravenek, W.; Rodríguez, J. I.; Ros, P.; Schipper, P. R. T.; van Schoot, H.; Schreckenbach, G.; Seldenthuis, J. S.; Seth, M.; Snijders, J. G.; Solà, M.; Swart, M.; Swerhone, D.; te Velde, G.; Vernooijs, P.; Versluis, L.; Visscher, L.; Visser, O.; Wang, F.; Wesolowski, T. A.; van Wezenbeek, E. M.; Wiesenekker, G.; Wolff, S. K.; Woo, T. K.; Yakovlev, A. L. $A D F$, ADF2014.06; SCM, Theoretical Chemistry, Vrije Universiteit: Amsterdam, The Netherlands, 2014.

10. van Lenthe, E.; Ehlers, A.; Baerends, E. J. Geometry optimizations in the zero order regular approximation for relativistic effects. J. Chem. Phys. 1999, 110, 8943-8953.

11. van Lenthe, E.; Baerends, E. J.; Snijders, J. G. Relativistic total-energy using regular approximations. J. Chem. Phys. 1994, 101, 9783-9792.

12. van Lenthe, E.; Baerends, E. J.; Snijders, J. G. Relativistic regular 2-component hamiltonians. J. Chem. Phys. 1993, 99, 4597-4610.

13. van Lenthe, E.; Snijders, J. G.; Baerends, E. J. The zero-order regular approximation for relativistic effects: 
The effect of spin-orbit coupling in closed shell molecules. J. Phys. Chem. 1996, 105, 6505-6516.

14. Grimme, S.; Antony, J.; Ehrlich, S.; Krieg, H. A consistent and accurate ab initio parametrization of density functional dispersion correction (DFT-D) for the 94 elements H-Pu. J. Chem. Phys. 2010, 132.

15. Grimme, S. Accurate description of van der Waals complexes by density functional theory including empirical corrections. J. Comput. Chem. 2004, 25, 1463-1473.

16. Pye, C. C.; Ziegler, T. An implementation of the conductor-like screening model of solvation within the Amsterdam density functional package. Theor. Chem. Acc. 1999, 101, 396-408.

17. Klamt, A.; Schüürmann, G. COSMO: a new approach to dielectric screening in solvents with explicit expressions for the screening energy and its gradient. J. Chem. Soc., Perkin Trans. 2 1993, 799-805.

18. Klamt, A.; Jonas, V.; Burger, T.; Lohrenz, J. C. W. Refinement and parametrization of COSMO-RS. J. Phys. Chem. A 1998, 102, 5074-5085.

19. Shamov, G. A.; Schreckenbach, G. Relativistic density functional theory study of dioxoactinide(VI) and (V) complexation with alaskaphyrin and related Schiff-base macrocyclic ligands. J. Phys. Chem. A 20o6, 110, 9486-9499.

20. Cai, H.-X.; Su, D.-M.; Zhao, H.-B.; Bacha, R. u. s.; Guo, Y.-R.; Pan, Q.-J. A DFT study on carbon dioxide reduction of low-valent diuranium complex supported by a polypyrrolic macrocycle. Chem. Phys. Lett. 2021, 776.

21. Yin, W.-M.; Wang, Y.; Hou, Y.-C.; Sun, Y.; Zhang, J.-G.; Sun, H.-L.; Li, S.-J.; Pan, Q.-J.; Guo, Y.-R. Petaloidarray hierarchically structured carbon Dots $/ \mathrm{Mg}(\mathrm{OH})(2)$ composite: Design, characterization and removal/recovery of cadmium via slowly releasing. Chem. Eng. J. 2020, 401.

22. Shah Bacha, R. U.; Li, L.; Guo, Y.-R.; Jing, L.; Pan, Q.-J. Actinyl-Modified g- $\mathrm{C}_{3} \mathrm{~N}_{4}$ as $\mathrm{CO}_{2}$ Activation Materials for Chemical Conversion and Environmental Remedy via an Artificial Photosynthetic Route. Inorg. Chem. 2020, 59, 8369-8379. 